\title{
Clinical Profile and Outcome of Acute Respiratory Failure in Children: A Prospective Study in a Tertiary Care Hospital
}

\author{
Jatinder Singh ${ }^{\mathrm{a}, \mathrm{b}}$, Vaneeta Bhardwar ${ }^{\mathrm{a}}$, Parveen Sobti ${ }^{\mathrm{a}}$, Puneet A Pooni ${ }^{\mathrm{a}}$
}

\begin{abstract}
Background: It was to study the clinical pattern of acute respiratory failure in children from 1 month to 15 years of age and to determine the outcome of respiratory failure in relation to underlying etiology and associated factors.
\end{abstract}

Methods: A hospital-based prospective study was conducted on 115 children in the age group from 1 month to 15 years. The duration of the study was 18 months. Acute respiratory failure was identified in any patient presenting with respiratory arrest or respiratory distress with $\mathrm{SpO}_{2}<90 \%$. The arterial blood gas (ABG) was done in all the patients showing signs of respiratory distress/altered respiratory pattern, and were included in the study if $\mathrm{PaO}_{2}<50 \mathrm{~mm}$ $\mathrm{Hg}$ and/or $\mathrm{PaCO}_{2}>60 \mathrm{~mm} \mathrm{Hg}$.

Results: Maximum patients (56.52\%) were observed in the age group of 1 month to 1 year and majority was males. Pulmonary diseases accounted for majority $(62.60 \%)$ of cases, followed by nervous system $(23.50 \%)$, sepsis $(9.56 \%)$ and cardiovascular system diseases $(4.34 \%)$. The respiratory failure was classified into three types based on ABG analysis, of which hypoxic respiratory failure (type 1) was the commonest $(74.78 \%)$. The commonest cause of respiratory failure and mortality was bronchopneumonia (42.60\%). About one-third of the patients (33.91\%) required ventilation support. Overall mortality rate was $14.14 \%$. Among the malnourished children maximum number had grade IV malnutrition, and the mortality rate increased with the grade of malnutrition.

Conclusion: The commonest type of respiratory failure was hy-

Manuscript accepted for publication March 31, 2014

\footnotetext{
${ }^{a}$ Department of Pediatrics, Dayanand Medical College and Hospital, Ludhiana, Punjab, India

${ }^{b}$ Corresponding Author: Jatinder Singh, Department of Pediatrics, Punjab Institute of Medical Sciences, Jalandhar, Punjab, India.

Email: jatvani@yahoo.co.in
}

doi: http://dx.doi.org/10.14740/ijcp145w poxic type, and bronchopneumonia was the commonest cause of mortality.

Keywords: Arterial blood gas analysis; Respiratory failure; Respiratory distress; Ventilatory support

\section{Introduction}

Acute respiratory failure may be defined as disruption in the function of the respiratory system that acutely impairs delivering adequate oxygen to or removing carbon dioxide from pulmonary capillary bed or both. It has varied etiologyrelated manifestations and has a high mortality in the pediatric age group [1]. The diagnosis of respiratory failure relies primarily on arterial blood gas (ABG) analysis. Early diagnosis can be made by the physician who has a high index of suspicion and who is aware of the clinical situations in which respiratory failure is likely to be a complication. If good clinical judgment and thorough knowledge of the natural history of the disease can be combined with a proper assessment of oxygenation, ventilation and acid base status, the management of many of patients can be exceptionally rewarding [2]. Careful assessment of history, complete physical examination and evaluation of laboratory parameters may clarify the diagnosis. Serial assessments of sensorium, respiratory symptoms, $\mathrm{ABG}$ and response to treatment provide valuable clues to determine the need for intervention [3]. Clinical signs of respiratory distress include tachypnea, altered depth of respiration, chest wall retraction, flaring of alae nasae, decreased breath sounds, grunting and cyanosis. In addition to cardiac signs like tachycardia, hypertension or bradycardia, hypotension and cardiac arrest can also be present. The diagnosis is confirmed by ABG. The recognition of respiratory failure as a life-threatening problem led to development of the concept of the intensive care unit (ICU) in modern hospitals. ICU personnel and equipment support vital functions to give patients' their best chance for recovery. Today's sophisticated ICU facilities with their novel mechanical lifesupport devices evolved as doctors and scientists learnt more 
Table 1. Relationship Between Diagnosis and Type of Respiratory Failure

Primary system involved/underlying disease

Number of cases

Respiratory system

Bronchopneumonia $\quad 49$

Asthma 5

Bronchiolitis 3

Aspiration pneumonia $\quad 5$

Aspiration of foreign body 1

Pneumothorax 1

SLE with lupus lung $\quad 2$

Laryngotracheobronchitis 3

Pleural effusion $\quad 1$

Thalassemia major with lobar pneumonia 1

Acute pancreatitis with lobar pneumonia

Cardiovascular system

Myocarditis with pulmonary edema $\quad 2$

FTT with anemia with CCF 1

VSD with pulmonary edema 2

Central nervous system

Viral hepatitis with encephalopathy 4

DKA with cerebral edema $\quad 4$

Meningitis $\quad 2$

Encephalitis 3

Cerebral malaria $\quad 2$

Guillain-barre syndrome $\quad 1$

Head injury 2

Status epilepticus $\quad 8$

Acute diarrhoeal disease with 1

Severe dehydration with meningitis

Others

Sepsis 11

and more about the cause of respiratory failure and how to treat it. In recent years, the rapid evolution of pediatric ICU (PICU) has stimulated an increasing need to understand the types of patients cared for in such units, their outcome and the services they require. In a developing country like India, very few centers are in a position to provide intensive care to the critically sick children. The present study was undertaken to determine the causes, clinical features and outcome of acute respiratory failure in children.

\section{Materials and Methods}

A prospective study was conducted over a period of 18 months on children from 1 month to 15 years of age, admitted with acute respiratory failure in the Department of Pediatrics at Dayanand Medical College and Hospital, Ludhiana, a tertiary care teaching institute in north India. All patients admitted in the pediatric emergency, with respiratory distress and/or respiratory failure at admission or within $6 \mathrm{~h}$ of admission, were included.

Criteria for acute respiratory failure was identified in any patient presenting with respiratory arrest or respiratory distress with $\mathrm{SpO}_{2}<90 \%$. The $\mathrm{ABG}$ was done in all patients. Acute respiratory distress was defined as changes in the respiratory rate, respiratory effort and work of breathing. Presence of head bobbing, grunting, stridor, prolonged exhalation, sub-costal and inter-costal recession, and decreased 


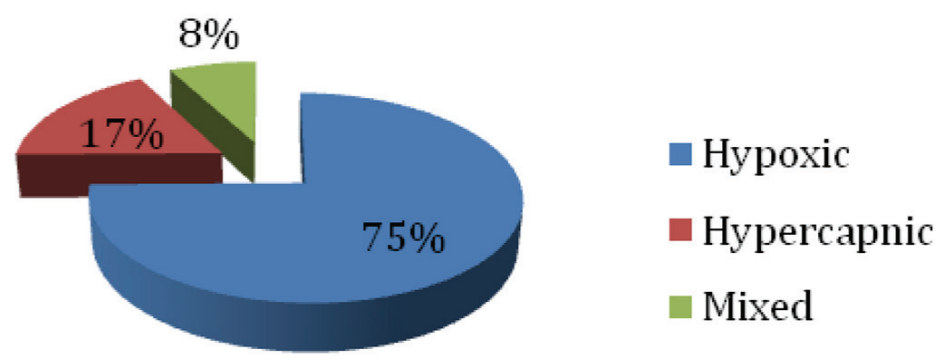

Figure 1. Pie chart showing distribution of type of respiratory failure.

chest expansion resulting from inadequate effort or airway obstruction were also included. Cardiac signs like weak and thready pulse, capillary refill time $>3 \mathrm{~s}$, cold, mottled, pale or cyanotic peripheries, pale mucous membranes or nail beds, tachycardia, hypertension and cerebral signs like presence of restlessness, irritability, headache, confusion, drowsiness and seizures were also suggestive of respiratory failure. Initially all the patients were managed in pediatric emergency and later shifted to PICU. The stable patients were shifted to the ward. All patients with signs of respiratory distress were attached to a pulse oximeter and enrolled in the study if $\mathrm{SpO} 2$ was $<90 \%$ on room air. Outcome was assessed in terms of survival/death, and was correlated with age, gender, nutritional status, duration of ambu bag/mechanical ventilation, complications of mechanical ventilation and the primary system involved. Nutritional status was assessed according to IAP PEM classification.

Z-test was used to compare two proportions of the patients and $\mathrm{P}$-value was obtained to assess the significance.

\section{Results}

Out of 115 cases of respiratory failure, maximum 65 $(56.52 \%)$ cases were observed in the age group of 1 month to 1 year followed by $23(20.00 \%)$ in the age group of 1 to 5 years, $16(13.91 \%)$ between 5 to 10 years and remaining $11(9.57 \%)$ in the age group of $>10$ years. The mean age at presentation was 36.96 months. There were $89(77.39 \%)$ males and $26(22.61 \%)$ females, with male:female ratio of 3.4:1. The most common clinical feature was fever seen in $79(68.70 \%)$ cases followed by irritability in $78(67.83 \%)$ and cough in $42(36.52 \%)$. Tachypnea and nasal flaring were the most common signs of respiratory distress seen in $103(89.57 \%)$ patients each. Chest retraction was a finding in $99(86.09 \%)$ patients and head bobbing was found in 83 $(72.17 \%)$ patients. All the patients presented with pale skin color. Cyanosis was seen in $30.43 \%$ cases. The capillary filling time was also estimated and it was $>3 \mathrm{~s}$ in $84(73.04 \%)$ patients.
The most common of respiratory failure in our study was bronchopneumonia seen in 49 cases $(42.60 \%)$ (Table 1$)$. The hypoxic respiratory failure (type 1) was the commonest type $(74.78 \%)$, followed by hypercapnic (type 2 ) respiratory failure in $20(17.39 \%)$. There were nine $(7.83 \%)$ cases of mixed respiratory failure (type 3 respiratory failure/combination of above two) (Fig. 1). Outcome of acute respiratory failure has been given in Table 2. Of the total 115 patients only $85(73.91 \%)$ survived with $76.92 \%$ and $72.73 \%$ survival rate in the age group $<1$ year and $>10$ years respectively. The commonest cause of death in respiratory failure was the bronchopneumonia $(50.00 \%)$ followed by sepsis in $14.29 \%$ cases. Other causes of high mortality rates were status epilepticus and diabetic ketoacidosis with cerebral edema in $14.29 \%$. Among the malnourished children, maximum number had grade IV malnutrition and of these $42.11 \%$ expired, only $26.32 \%$ were discharged and $31.58 \%$ left against medical advice. Patient who left against medical advice was on IPPV with ambu.

Type 1 respiratory failure had higher mortality rate of $13.95 \%$ as compared to patients with type 2 or type 3 respiratory failures. Of the total 115 patients only 39 (33.91\%) patients received ventilatory support with $43.59 \%$ survival. Of these $17(43.59 \%)$ patients were on ventilatory support for $>72 \mathrm{~h}$ with $58.82 \%$ survival which was better than in those who received ventilation for less duration. This association was significant with $\mathrm{P}$-value $<0.05$. Of the total 115 patients 42 patients were malnourished. Among the malnourished children maximum number i.e. 19 (45.23\%) cases had grade IV malnutrition and the mortality rate increased with the grade of malnutrition $(\mathrm{P}<0.05)$.

\section{Discussion}

Respiratory failure is defined as inability to meet one's need for tissue oxygenation and elimination of $\mathrm{CO}_{2}$, often but not always associated with distress. Respiratory failure develops when the rate of gas exchange between the atmosphere and blood is unable to match the body's metabolic demands. It 
Table 2. Outcome of Acute Respiratory Failure

\section{Outcome*}

Feature

$\begin{array}{llll}\text { No. of cases } & \text { Survived } & \% & \text { Died }\end{array}$

Age

0.10

$\begin{array}{llllll}1 \text { month }-1 \text { year } & 65 & 50 & 76.92 & 6 & 9.23 \\ 1 \text { year }-5 \text { years } & 23 & 16 & 69.57 & 1 & 4.35 \\ 5 \text { years }-10 \text { years } & 16 & 11 & 68.75 & 4 & 25.00 \\ >10 \text { years } & 11 & 08 & 72.73 & 3 & 27.27\end{array}$

Nutritional status

0.05

$\begin{array}{llllll}\text { Normal } & 73 & 70 & 95.89 & 1 & 1.37 \\ \text { Grade I PEM } & 06 & 04 & 66.67 & 1 & 16.67 \\ \text { Grade II PEM } & 07 & 03 & 42.86 & 1 & 14.29 \\ \text { Grade III PEM } & 10 & 03 & 30.00 & 3 & 30.00 \\ \text { Grade IV PEM } & 19 & 05 & 26.32 & 8 & 42.11\end{array}$

Type of respiratory failure

$\begin{array}{llllll}\text { Type } 1 & 86 & 63 & 73.26 & 12 & 13.95 \\ \text { Type } 2 & 20 & 15 & 75.00 & 01 & 05.00 \\ \text { Type 3 } & 9 & 07 & 77.78 & 01 & 11.11\end{array}$

Duration of ventilation

$\begin{array}{ll}\text { No ventilation } & 76 \\ 1-24 \mathrm{~h} & 7 \\ 24-72 \mathrm{~h} & 15 \\ >72 \mathrm{~h} & 17\end{array}$

$\begin{array}{lllll}76 & 68 & 89.47 & 2 & 2.63 \\ 7 & 0 & 00 & 6 & 85.77 \\ 15 & 07 & 46.67 & 3 & 20.00 \\ 17 & 10 & 58.82 & 3 & 17.65\end{array}$

Inotropes

Yes

46.88

84.33

0.10

0.05

-value

No 83

${ }^{*}$ Outcome is excluding LAMA patients.

is diagnosed when the patient loses the ability to provide sufficient oxygen to the blood and develops hypoxemia or when the patient is unable to adequately ventilate and develops hypercarbia. Acute respiratory failure remains a major cause of morbidity and mortality in both pediatric and adult populations. The annual incidence in the United States is as high as 150,000 cases, with mortality rates generally ranging between $50 \%$ and $70 \%$ [4]. Recent studies of acute respiratory distress syndrome (ARDS) in children report a 60-75\% mortality rate [5-7]. Sepsis and multiple organ system dysfunction contribute the most to the high mortality and mor- bidity seen in both adults and children with ARDS.

The maximum number of patients in our study was in the age group of 1 month to 1 year. This is in accordance with study done by Karande et al [8] in which the majority of cases $(52 \%)$ were in this similar age group. Similarly another study done in by Newth [2] found that in almost two-thirds of the cases, respiratory failure occurred in the first year of life. This high incidence of respiratory failure in infancy could be attributed to structural immaturity of the chest wall, respiratory muscles and the airways. This can also be explained by defining anatomic compartments and 
their developmental differences in pediatric patients that influence susceptibility to acute respiratory failure. Males were 3.4 times more frequently affected than females in our study. Similar results were found in a study by Fresca et al where male:female ratio of 1.27:1 i.e. male predominance was observed [9]. However, ratio in our study was high which can be due to gender bias i.e. more male patients brought to the hospital. Hypoxic respiratory failure (type 1) was characterized by $\mathrm{PaO}_{2}<50 \mathrm{~mm} \mathrm{Hg}$ and was the commonest type seen in $74.78 \%$ of patients. Similar study done by Fresca et al in 128 non-neonate pediatric patients, observed that hypoxic respiratory failure (type 1) was the commonest type constituting $94.50 \%$ of total patients [9].

The most common clinical features were fever and irritability, followed by cough and cyanosis. Karande et al noticed cyanosis in $52 \%$ cases and irritability in 64\% [8]. Similar study by Singhi also concluded that fever, cough and cyanosis were commonly seen symptoms of respiratory distress [10]. The common signs of respiratory distress were tachypnea, nasal flaring, head bobbing and chest retractions of which tachypnea and nasal flaring were most common seen in patients. Similar observations were made in a study by Karande et al [8]. The commonest cause of respiratory failure was acute bronchopneumonia. The overall mortality rate was $14.14 \%$. This is not in accordance with the various studies as by Ferring et al [11] and Hussain et al [12] who reported high mortality rate in patients with respiratory failure of $28 \%$ and $52 \%$ respectively. The low mortality in present study than other studies was probably because of the factors that included early presentation of the child and hence early treatment, less number of patients with malnutrition and timely ventilation. The $58.62 \%$ of patients who required ventilator support survived. On the other hand, the patients who did not require ventilatory support, $97.14 \%$ survived. There was statistically significant correlation between the ventilatory support (including the duration of ventilator support) and the outcome. The coexistent malnutrition was associated with significantly higher mortality (P-value $<0.05$ ). This is in accordance with the previous studies that showed that the response to treatment and outcome are affected by associated malnutrition, i.e. with increasing malnutrition there is decreased response to treatment and poor outcome $[8,13]$. In summary, acute respiratory failure and its outcome were independent of age of the child. Malnutrition and type 1 failure were associated with poor outcome.

\section{References}

1. Pediatrics Advanced Life Support (PALS) Provider Manual, American Academy of pediatrics, American Heart Association - Recognition of respiratory Failure. 2002;29.

2. Newth CJ. Recognition and management of respiratory failure. Pediatr Clin North Am. 1979;26(3):617-643.

3 . Ranjit S. Acute respiratory failure and oxygen therapy. Indian J Pediatr. 2001;68(3):249-255.

4. Bernard GR, Artigas A, Brigham KL, Carlet J, Falke K, Hudson L, Lamy M, et al. The American-European Consensus Conference on ARDS. Definitions, mechanisms, relevant outcomes, and clinical trial coordination. Am J Respir Crit Care Med. 1994;149(3 Pt 1):818-824.

5. Timmons OD, Dean JM, Vernon DD. Mortality rates and prognostic variables in children with adult respiratory distress syndrome. J Pediatr. 1991;119(6):896-899.

6. Davis SL, Furman DP, Costarino AT, Jr. Adult respiratory distress syndrome in children: associated disease, clinical course, and predictors of death. J Pediatr. 1993;123(1):35-45.

7. DeBruin W, Notterman DA, Magid M, Godwin T, Johnston S. Acute hypoxemic respiratory failure in infants and children: clinical and pathologic characteristics. Crit Care Med. 1992;20(9):1223-1234.

8. Karande S, Murkey R, Ahuja S, Kulkarni M. Clinical profile and outcome of acute respiratory failure. Indian $\mathrm{J}$ Pediatr. 2003;70(11):865-869.

9. Fresca S, Srinivas K. Extracorporeal life support outcome for 128 pediatric patient with acute respiratory failure. J Pediatr Sug. 2000;35:197-202.

10. Singhi S. Acute respiratory distress. Text book on medical emergencies in children. 2000;295-319.

11. Ferring M, Vincent JL. Is outcome from ARDS related to the severity of respiratory failure? Eur Respir J. 1997;10(6): 1297-1300.

12. Hussain SF, Irfan M, Naqi YS, Islam M, Akhtar W. Acute respiratory failure in Pakistani patients: risk factors associated with mortality. J Coll Physicians Surg Pak. 2006;16(4):287-290.

13. Doekel RC, Jr., Zwillich CW, Scoggin CH, Kryger M, Weil JV. Clinical semi-starvation: depression of hypoxic ventilatory response. N Engl J Med. 1976;295(7):358361 . 